\title{
Identifying Conserved Generic Aspergillus spp. Co-Expressed Gene Modules Associated with Germination Using Cross-Platform and Cross-Species Transcriptomics
}

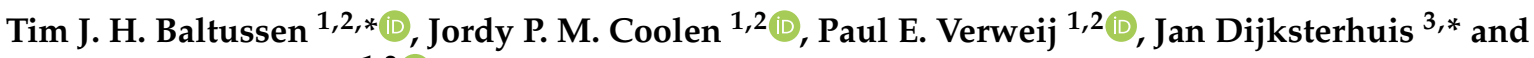 \\ Willem J. G. Melchers ${ }^{1,2}$ (D) \\ 1 Department of Medical Microbiology, Radboud Institute for Molecular Life Sciences, Radboud University \\ Medical Center, 6525 GA Nijmegen, The Netherlands; Jordy.Coolen@radboudumc.nl (J.P.M.C.); \\ Paul.Verweij@radboudumc.nl (P.E.V.); Willem.Melchers@radboudumc.nl (W.J.G.M.) \\ 2 Center of Expertise in Mycology Radboudumc/CWZ, 6532 SZ Nijmegen, The Netherlands \\ 3 Westerdijk Fungal Biodiversity Institute, 3584 CT Utrecht, The Netherlands \\ * Correspondence: Tim.Baltussen@radboudumc.nl (T.J.H.B.); j.dijksterhuis@wi.knaw.nl (J.D.)
}

check for updates

Citation: Baltussen, T.J.H.; Coolen, J.P.M.; Verweij, P.E.; Dijksterhuis, J.; Melchers, W.J.G. Identifying

Conserved Generic Aspergillus spp. Co-Expressed Gene Modules Associated with Germination Using Cross-Platform and Cross-Species

Transcriptomics. J. Fungi 2021, 7, 270. https://doi.org/10.3390/jof7040270

Academic Editor: David Perlin

Received: 22 February 2021

Accepted: 29 March 2021

Published: 1 April 2021

Publisher's Note: MDPI stays neutral with regard to jurisdictional claims in published maps and institutional affiliations.

Copyright: (c) 2021 by the authors. Licensee MDPI, Basel, Switzerland. This article is an open access article distributed under the terms and conditions of the Creative Commons Attribution (CC BY) license (https:// creativecommons.org/licenses/by/ $4.0 /)$.

\begin{abstract}
Aspergillus spp. is an opportunistic human pathogen that may cause a spectrum of pulmonary diseases. In order to establish infection, inhaled conidia must germinate, whereby they break dormancy, start to swell, and initiate a highly polarized growth process. To identify critical biological processes during germination, we performed a cross-platform, cross-species comparative analysis of germinating $A$. fumigatus and $A$. niger conidia using transcriptional data from published RNA-Seq and Affymetrix studies. A consensus co-expression network analysis identified four gene modules associated with stages of germination. These modules showed numerous shared biological processes between $A$. niger and $A$. fumigatus during conidial germination. Specifically, the turquoise module was enriched with secondary metabolism, the black module was highly enriched with protein synthesis, the darkgreen module was enriched with protein fate, and the blue module was highly enriched with polarized growth. More specifically, enriched functional categories identified in the blue module were vesicle formation, vesicular transport, tubulin dependent transport, actindependent transport, exocytosis, and endocytosis. Genes important for these biological processes showed similar expression patterns in A. fumigatus and A. niger, therefore, they could be potential antifungal targets. Through cross-platform, cross-species comparative analysis, we were able to identify biologically meaningful modules shared by $A$. fumigatus and $A$. niger, which underscores the potential of this approach.
\end{abstract}

Keywords: aspergillus; germination; consensusWGCNA; isotropic growth; polarized growth; RNASeq; microarray

\section{Introduction}

The genus Aspergillus consists of at least 450 species [1] that occur worldwide and are members of all habitats. They grow in soil, are associated with plants, and even colonize oceans. The genus coexists with other living organisms, and this association regularly develops into an (opportunistic) pathogenicity, for example Aspergillus sydowii on coral reefs and Aspergillus niger on onions [2,3]. One of the important means of distribution within the genus are single-celled survival structures, called conidia, that are released into the air. Conidia of fungal species in different genera, including Aspergillus, are globally distributed [4], and, due to their small size, can enter the lungs of animals, including humans [5]. These conidia contain a rodlet layer that effectively shields them from the human immune system, but rarely causes infections [6,7]. Nevertheless, with Aspergilli that can grow at hypoxic conditions and body temperatures, and with a person with immune deficiencies, a serious risk for infection develops. In the case of $A$. fumigatus, 
and to a lesser extent the species $A$. flavus, $A$. niger, $A$. terreus, and $A$. nidulans, this can lead to severe lung disease, including chronic pulmonary aspergillosis (CPA) and invasive aspergillosis (IA).

CPA is estimated to affect 3 million people worldwide, and more than 200,000 people are affected by IA each year [8,9]. The overall mortality rate of IA is $50 \%$ even if diagnosed and treated, but if diagnosis is delayed or missed, or if infection is caused by an antifungal-resistant strain, then mortality may increase to nearly $100 \%$ [8]. Although IA is traditionally observed in patients with neutropenia, over the past few decades, increasingly non-neutropenic hosts are at risk of developing IA, including patients with severe influenza and coronavirus disease (COVID-19) [10,11]. The pathogenesis of IA is characterized by the germination of inhaled conidia, and, if not internalized by epithelial cells and phagocytized by alveolar macrophages, hyphal growth and penetration into lung tissue $[5,12]$.

Germination of inhaled conidia is crucial to establish an infection in the host. Although dormant conidia may be immunologically inert, once germinating, they are able to express a repertoire of factors that enable them to develop and grow in lung tissue [5]. After a conidium breaks dormancy, the germination is characterized by two stages: isotropic growth and polarized growth. Dormant conidia are protected by intra- and extracellular molecules, among them proteins, against unfavorable conditions, such as oxidative stress, variations in $\mathrm{pH}$, osmotic pressure, dehydration, thermal stress, and UV radiation [13]. Breaking of dormancy in Aspergillus conidia initiates the transition of a resting cell into a vegetative active cell, and, in a number of cases, transition is the result of the presence of nutrients in the environment, such as sugars and amino acids [14-17]. Breaking of dormancy includes a massive reorganization of the transcriptome [18,19] and degradation of compatible solutes [20], and is accompanied by an increase of the cellular perimeter dubbed isotropic growth ("swelling") [21]. Isotropic swelling of the conidia is followed by polarized growth. In this phase, the growth is directed to a local region on the cell surface [22], which results in the formation of a germ tube [18,22-27].

Transcriptomic and proteomic studies over the past two decades have provided important information on genes and proteins involved in germination [18,19,23-26,28-36]. Remodelling of the cell wall, together with metabolic activities required for cellular growth, such as protein synthesis and carbohydrate metabolism, are important during isotropic growth. These metabolic activities, together with the functional organization of the hyphal tip and the cell cycle machinery, are important during polarized growth. A more profound understanding of the transitions from dormant conidia via germ tube initiation to hyphal tip formation may be vital in the search for possible novel strategies to eradicate early infection.

In this study, we performed a cross-platform, cross-species comparative analysis of germinating $A$. fumigatus and $A$. niger conidia using transcriptional data from two published studies $[18,23]$. The different transcriptional datasets were integrated into one, and a consensus co-expression network analysis was applied to identify common biological processes during germination.

\section{Materials and Methods}

\subsection{Transcriptomic Data}

In this study, published transcriptomic data of germinating $A$. fumigatus and $A$. niger conidia were used $[18,23]$. The raw data were accessed through the NCBI Gene Expression Omnibus (GEO) accession number GSE36439 (GEO. Available online: www.ncbi.nlm. nih.gov/geo/ accessed on 24/03/2020) and the NCBI Sequence Read Archive (SRA) accession number PRJNA408076 (SRA. Available online: https: / /www.ncbi.nlm.nih.gov / sra accessed on 24/03/2020). The $A$. fumigatus data were obtained via Illumina RNA-Seq and the $A$. niger data via Affymetrix A. niger Genome Genechips. The $A$. niger strain N402 [37] and A. fumigatus strains AfIR974 and AfIR964 were used in the studies. 


\subsection{Orthology Inference Using Reciprocal Best Hits (RBH) Method}

To compare the transcriptomic profiles of A. fumigatus and A. niger, pairs of genes were identified in two different genomes using the RBH method. This method entails that the pairs of genes between two species are more similar to each other than to any other gene in the other genome [38]. NCBI's BLAST (version 2.10.1+) was first used to create two databases of the protein sequences of A. fumigatus af293 [39] and A. niger CBS513.88 [40]. The $A$. fumigatus annotated protein sequences were downloaded from Ensembl Fungi (available online: http:/ ftp.ebi.ac.uk/ensemblgenomes/pub/release-30/fungi/fasta/ aspergillus_fumigatus/, accessed on 06/10/2020 (Aspergillus_fumigatus.CADRE.30.pep. all.fa)). The $A$. niger annotated protein sequences were downloaded from Aspergillus Genome Database (available online: http:/ / www.aspgd.org/, accessed on 06/10/2020 (A_niger_CBS_513_88_orf_trans_all.20110819.fasta)). The specific command lines used to build the protein sequence databases of A. fumigatus and A. niger are presented in Table S1.

A BLASTp all vs. all was performed using the $A$. fumigatus protein sequences as the query and the $A$. niger protein database as the subject, and vice versa. The command lines used for this query protein to subject protein comparison are presented in Table S1. The additional options for blastp were a final Smith-Waterman alignment and a maximum e-value threshold of $1 \times 10^{-6}$ [41]. Additional requirements were a query coverage per subject of $60 \%$, a minimum bit score of 80 , and a minimum percent identify of 30 . For selecting the RBH hits results, the query protein to subject protein comparisons were first sorted from lowest to highest e-values, then from highest to lowest bit scores. After sorting the results, the first hit for each query was therefore the best hit. Finally, each first hit in the first direction was compared with the first hit for each query in the opposite direction. Using the RBH method, we identified 6,598 orthologous genes between A. fumigatus and A. niger.

\subsection{Data Integration and Exploratory Analysis}

The gene pairs were used to integrate the RNA-Seq dataset with the microarray dataset. The datasets of $A$. fumigatus and A. niger contained 19 and 15 samples, respectively. In the first step, the merge function from the base $\mathrm{R}$ package was used to combine both sets based on the identified gene pairs [42]. The integrated dataset was log transformed using the $\log 1 p$ function from the $R$ base package, which computes $\log _{e}(1+x)$ [42]. A principal component analysis was performed on the log transformed data. The pca and biplot functions from the R package PCA tools were used to generate the principal components and corresponding plots [43]. Next, normalization of the integrated dataset was applied using the NormalizeBetweenArrays function from the limma R package [44], as previously proposed by Castillo et al. [45]. The $\mathrm{R}$ package ggplot2 was used to plot the data before and after normalization [46].

\subsection{Consensus Weighted Gene Co-Expression Network Analysis (consensusWGCNA)}

The integrated dataset was analyzed using a constructed consensus network. The network was built using the WGCNA R package $[47,48]$. The integrated dataset was put into a multi-set format suitable for consensus analysis. The trait data were matched with the expression samples for which they were measured. The corresponding traits were dormant $(0 \mathrm{~h})$, isotropic growth $(2 \mathrm{~h}, 4 \mathrm{~h})$, and polarized growth $(6 \mathrm{~h}, 8 \mathrm{~h})$. Construction of the weighted gene network entails the choice of a soft thresholding power $\beta$. The power $\beta$ of 13 $\left(\mathrm{R}^{2}\right.$ of 0.82$)$ was chosen based on the criterion of approximate scale-free topology [49]. The function blockwiseConsensusModules was used for network construction and consensus module detection. Other thresholds included a minimum module size of 30 , a cut height for the merging of modules of 0.30 (modules whose eigengenes were correlated above 0.7 were merged), correlation option Pearson (corType), adjacency function option (networkType) signed hybrid, and a topological overlap option (TOMType) signed. The soft power $\beta$ was used to calculate the Pearson's correlation between all genes. To minimize the effects of noise and spurious associations, the adjacency matrix was converted to a consensus 
topological overlap measure (TOM). For calculation of the consensusTOM, individual TOMs were scaled by full quantile normalization (networkCalibration = full quantile). The modules detected by the blockwiseConsensusModules function were assigned a random color. For each module, a module eigengene was calculated by the first principal component. The module eigengene could be regarded as the best representation of the gene expression patterns of that module. Next, trait data and module eigengenes were used to calculate the module-trait relationships by using the Pearson's correlation between the trait of interest and the module eigengene. To summarize the two sets into one (i.e., for detection of modules with similar correlation to the external traits), we used a conservative method: for each module-trait pair, we took the correlation that had the lower absolute value in the two sets if the two correlations had the same sign, and zero relationship if the two correlations had opposite signs. Modules with a correlation $\geq|0.70|$ and $p$-value $\leq 0.01$ were selected for further analyses.

\subsection{Functional Classification}

Consensus modules that were correlated with any of the growth phases were selected for functional enrichment analysis to understand the biological function of the modules. To analyze the corresponding gene lists, we used the online webtool FungiFun2 (version 2.2.8) and used the functional ontologies from the Functional Catalogue (FunCat) [50,51]. The default settings of the FungiFun2 webtool were used, except for the background; as the background, the 6598 identified orthologous genes were used.

\section{Results}

\subsection{Orthology Inference, Data Integration, and Exploratory Analysis}

The transcriptomic data used in this comparative study were generated by two different transcriptional profiling platforms (i.e., Illumina NextSeq500 and Affymetrix A. niger Genome Genechips). For identification of orthologous gene pairs between the two species, the RBH method was used, which resulted in 6598 orthologous gene pairs. Next, the identified orthologs were used to integrate the datasets from both RNA-Seq and microarray technologies. The first two principal components are plotted in Figure 1 to visualize the similarities and dissimilarities between the samples. The integrated dataset was log transformed using the $\log 1 \mathrm{p}$ function to avoid the variance measure being dominated by highly expressed, highly variable genes [42,52]. Variation between the two species was explained by the first principal component, whereas variation between the different time points was explained by the second and third principal component. Variation in microarray data between germinating $A$. niger conidia ( $2-8 \mathrm{~h}$ ) were small, as those samples were clustered together on PC2. Only the $0 \mathrm{~h}$ samples of $A$. niger were substantially different from all other time points. Larger variations were observed between $A$. fumigatus RNA-Seq samples, with dissimilarities between the $2-4 \mathrm{~h}$ samples and $6-8 \mathrm{~h}$ samples. The $0 \mathrm{~h}$ samples were substantially different from the 6-8 $\mathrm{h}$ samples. The third principal component was plotted to better explore the variation between the samples of $A$ niger. Variation between $A$. niger samples was explained by $\mathrm{PC} 3$ rather than PC2, whereas variation between $A$. fumigatus samples was explained by PC2 and PC3.

The raw data, i.e., RNA-Seq counts and microarray fluorescence intensities, are plotted in Figure 2A to show the difference of the dynamic range between the datasets. A larger dynamic range of the RNA-Seq samples was observed compared with microarray samples. Figure $2 \mathrm{~B}$ shows the results of the joint normalization, where the dynamic range between the samples has been corrected. The outliers were left out of Figure 2 for better visualization of the data. Normalized data including outliers are plotted in Figure S1. 


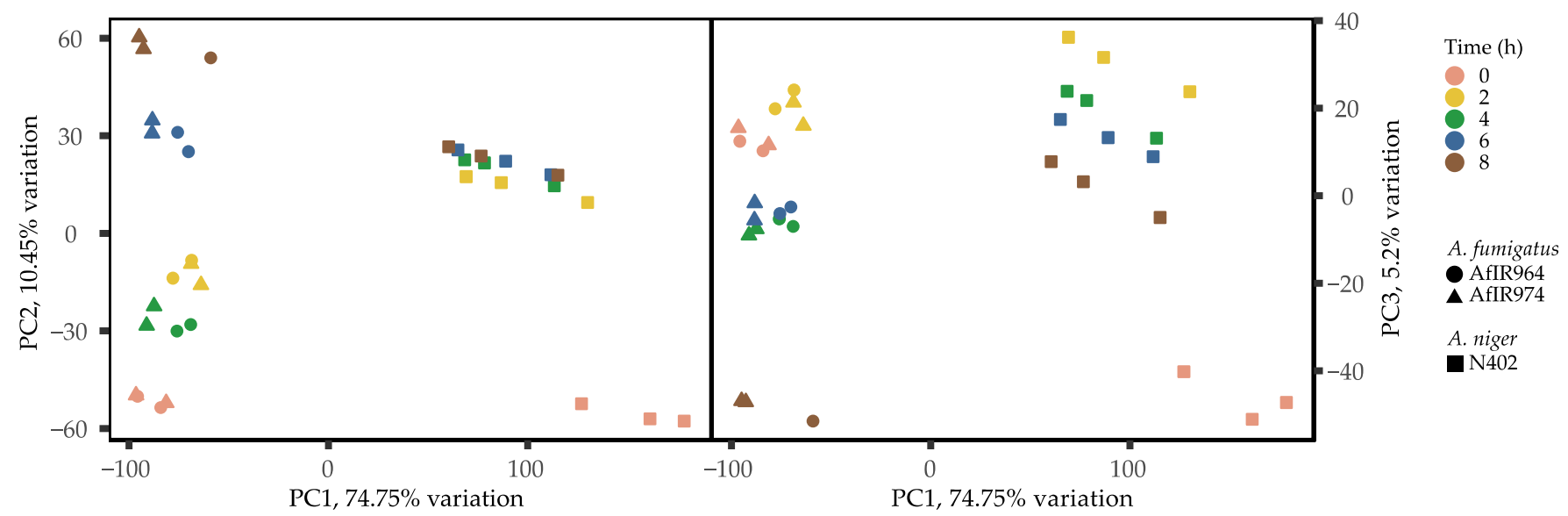

Figure 1. Principal component analysis of the log transformed expression data. The left plot shows PC1 on the $x$-axis and PC2 on the $y$-axis. The right plot shows PC1 on the $x$-axis and PC 3 on the $y$-axis.
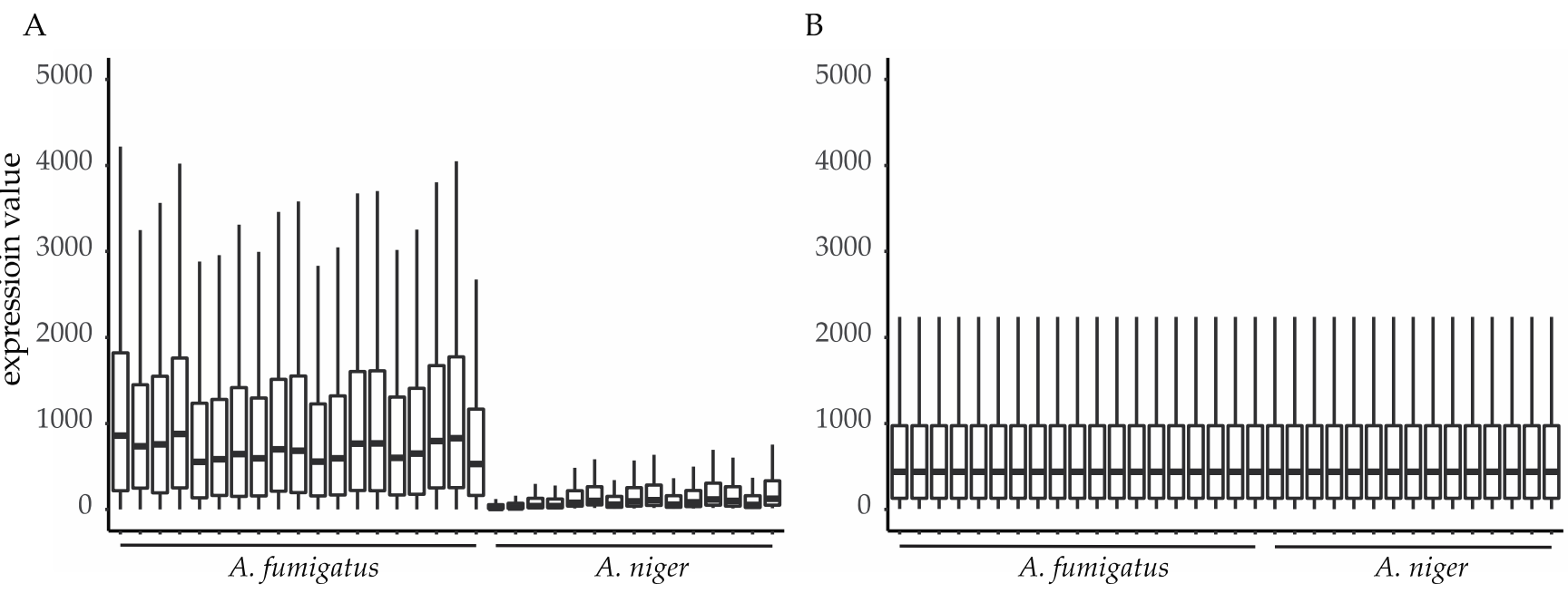

Figure 2. Expression profiles of the A. fumigatus and A. niger datasets before normalization (A) and after normalization (B). Outliers were left out of the figure for better visualization of the data.

\subsection{Consensus Co-Expression Network Analysis}

To examine the transcriptomic similarities between germinating A. fumigatus and $A$. niger conidia, we constructed a consensus gene co-expression network. Co-expression networks constructed from gene expression data suggest functional relationships between genes [49,53]. Consensus modules may contain shared biological pathways between the compared datasets. The consensusWGCNA detected 25 highly co-expressed gene modules that varied greatly in size (41-992 genes). Each module was labelled by a color, and, henceforth, we will refer to each module by its corresponding color.

Next, we used the module eigengenes to relate the consensus modules to external sample information. An eigengene is the first principal component of that module, and may be regarded as a representative of the gene expression patterns in the corresponding module. The external trait information was matched with the expression samples for which they were measured. The defined traits were dormant $(0 \mathrm{~h})$, isotropic growth $(2 \mathrm{~h}$, $4 \mathrm{~h})$, and polarized growth $(6 \mathrm{~h}, 8 \mathrm{~h})$. Each gene was assigned to a single module, but each module had two consensus module eigengenes. This was because each orthologous gene had a particular expression pattern in A. fumigatus and a different expression pattern in A. niger. To determine if any of the 25 modules were associated with the traits, we calculated the correlation of the module eigengenes with each trait for $A$. fumigatus and $A$. 
niger (Figure 3A,B). To identify the modules that were highly correlated to any of the traits in both species (consensus modules), the two sets were summarized into one: for each module-trait, pair we took the correlation that had the lower absolute value in the two sets if the two correlations had the same sign, and zero relationship if the two correlations had opposite signs (Figure 3C). Only modules that had a significant correlation with an external trait are shown in Figure 3A-C. The turquoise and black modules were highly correlated to the dormant phase ( 0.89 and -0.72 , respectively), midnightblue was correlated to isotropic growth (0.82), and the darkgreen and blue modules were highly correlated to polarized growth ( 0.73 and 0.79 , respectively). For all 25 modules and corresponding correlation and $p$-values to the traits, see supplemental Figures S2 and S3.

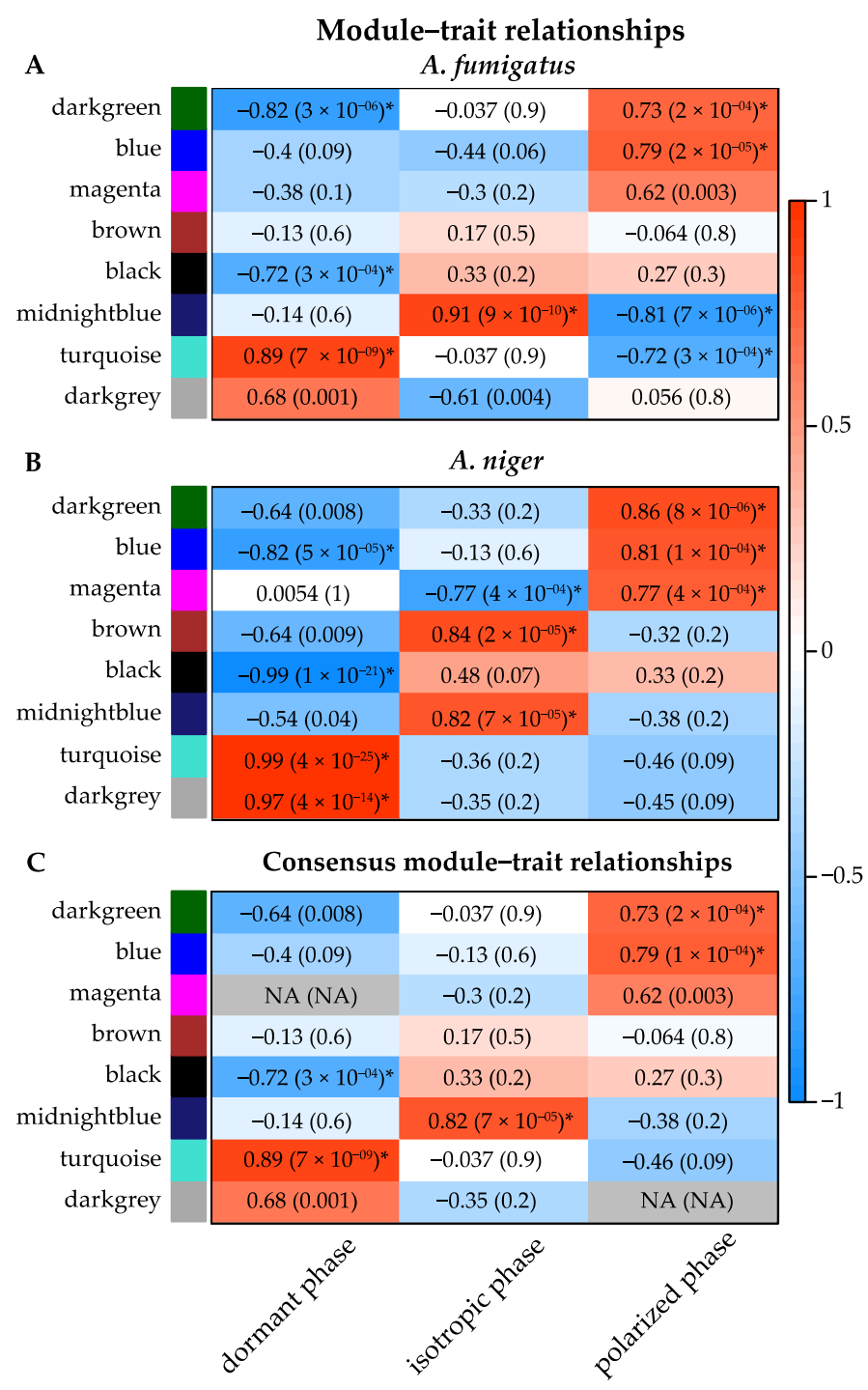

Figure 3. Module-trait relationships (A,B). Correlation of the module eigengenes (row) for $A$. fumigatus and $A$. niger with the external trait (column). (C) Correlation of the consensus modules with the external trait: A and B are summarized into one, where the lowest correlation score was used if the two correlations had the same sign, and zero relationships if the two correlations had opposite signs (NA). The module eigengenes correlation and $p$-value to the external trait are indicated in the cells and colored by the strength of the correlation. Red is a strong positive correlation compared to the dormant phase, while blue is a strong negative correlation compared to the dormant phase. * Significant modules have a correlation $\geq|0.70|$ and $p$-value $\leq 0.01$. Only modules that have a significant correlation with an external trait are shown in this figure. 
To retrieve the biological function of the highly correlated consensus modules, we performed a functional enrichment analysis using functional ontologies from FunCat [51]. The consensus module midnightblue did not show any significant results $(p>0.05)$. The turquoise module was found to represent mostly secondary metabolism and fatty acid and carbohydrate metabolism. The black module was highly enriched with protein synthesis genes, the darkgreen module was enriched with ubiquitin-related genes, and the blue module was highly enriched in polarized growth genes. The detailed results are shown in Figures 4 and 5 and Table S2. The specific biological processes and molecular functions identified in each of the significant modules (i.e., turquoise, black, darkgreen, and blue) are described in the next section. Closely related co-expression modules may form a biologically meaningful meta-module. In Figure 6, the clustering dendrogram of consensus module eigengenes is plotted for identifying meta-modules. The meta-modules are further described in next section.

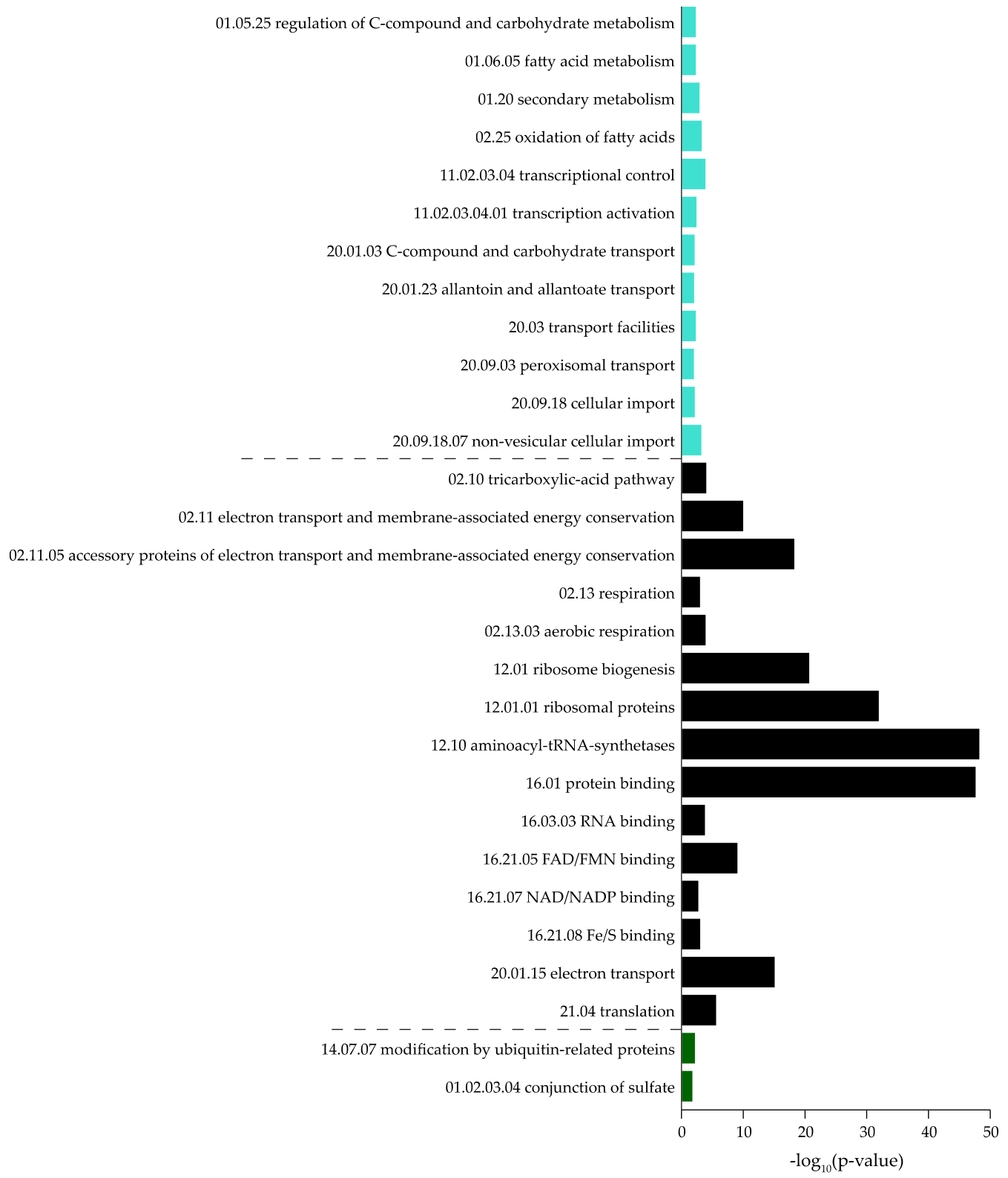

Figure 4. Functional categorization of the turquoise, black, and darkgreen modules. 
02.45.11 conversion to kinetic energy (e.g. movement)

02.45.15 energy generation (e.g. ATP synthase)

10.03 cell cycle

10.03.01 mitotic cell cycle and cell cycle control 10.03.01.01 mitotic cell cycle 10.03.01.01.11 M phase 10.03.01.03 cell cycle checkpoint 10.03.03 cytokinesis (cell division) /septum formation and hydrolysis 10.03.04 nuclear and chromosomal cycle 10.03.04.05 chromosome segregation/division 10.03.04.09 nuclear migration 10.03.05.01 spindle pole body/centrosome and microtubule cycle 10.03.05.03 cell cycle dependent actin filament reorganization 14.04 protein targeting, sorting and translocation 14.07.01 modification with fatty acids 14.07.02 modification with sugar residues 14.07.02.02 N-directed glycosylation, deglycosylation 14.07.03 modification by phosphorylation, dephosphorylation, autophosphorylation 14.07.07 modification by ubiquitin-related proteins 14.07.11 protein processing (proteolytic) 14.10 assembly of protein complexes 14.13.01 cytoplasmic and nuclear protein degradation 14.13.01.01 proteasomal degradation (ubiquitin/proteasomal pathway) 16.01 protein binding 16.06 motor protein binding 16.07 structural protein binding 16.17.01 calcium binding 16.19.05 GTP binding 18.01.01 regulation by modification 18.02.01 enzymatic activity regulation / enzyme regulator 18.02.01.01.01 GTPase activator (GAP) 18.02.05 regulator of G-protein signalling 20.01.10 protein transport 20.09.05 non-vesicular ER transport 20.09.07 vesicular transport (Golgi network, etc.) 20.09.07.03 ER to Golgi transport 20.09.07.05 intra Golgi transport

20.09.07.25 vesicle formation 20.09.13 vacuolar/lysosomal transport 20.09.14 cytoskeleton-dependent transport 20.09.14.01 tubulin dependent transpor 20.09.14.02 actin dependent transport 20.09.16.09.03 exocytosis 20.09.18.09.01 endocytosis 20.09.18.09.01.01 receptor-mediated endocytosis 30.01 cellular signalling

30.01.05 enzyme mediated signal transduction 30.01.05.05.01 small GTPase mediated signal transduction 30.05 transmembrane signal transduction 32.01 stress response 32.01 .03 osmotic and salt stress response 34.01.01.03 homeostasis of protons 34.05 cell motility 34.05.02 motor activity 34.07 cell adhesion

40.01 cell growth / morphogenesis 40.01.03 directional cell growth (morphogenesis) 41.01.01 mating (fertilization) 42.01 cell wall 42.04 cytoskeleton/structural protein 42.04.03 actin cytoskeleton 42.04.05 microtubule cytoskeleton 42.07 endoplasmic reticulum 42.09 intracellular transport vesicles 42.29 bud / growth tip 43.01.03.05 budding, cell polarity and filament formation 43.01.03.09 development of asco- basidio- or zygospore

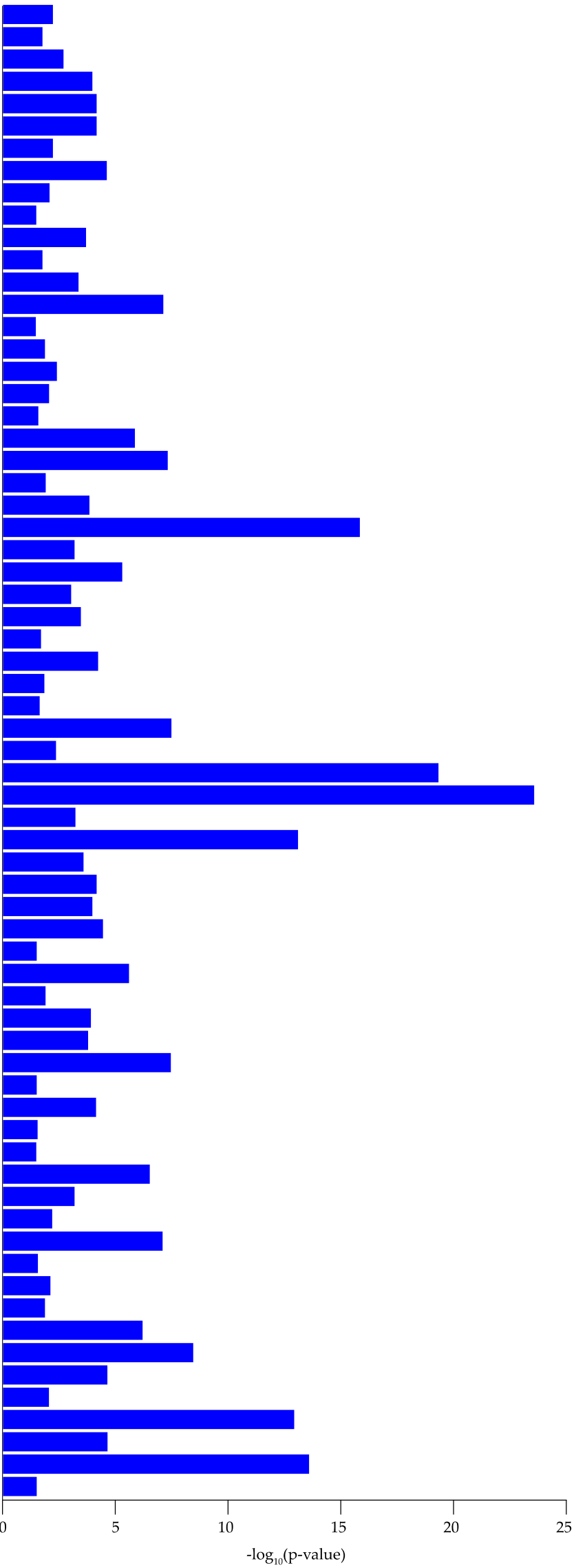

Figure 5. Functional categorization of the blue module. 


\section{Clustering of consensus module eigengenes}

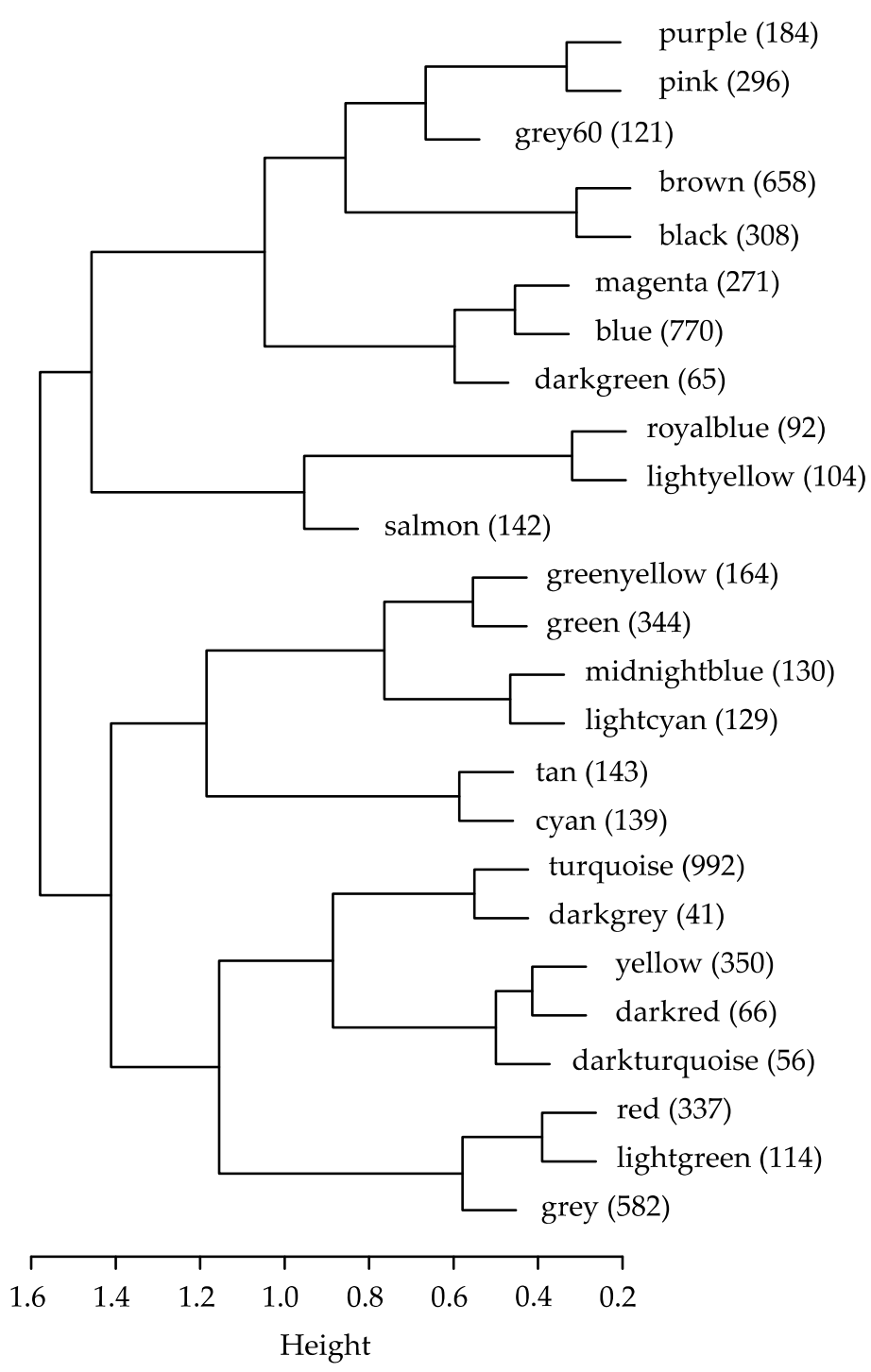

Figure 6. Clustering dendrogram of consensus module eigengenes for identifying meta-modules. Modules were clustered using the first principal component to form a dendrogram of consensus module eigengenes, representing the relation in expression between the consensus module eigengenes. The number of genes in each module is indicated between parentheses.

\subsection{Modules}

\subsubsection{Turquoise}

The turquoise module contained 992 genes, and was the largest module detected by the consensusWGCNA. The gene expression patterns in this module showed that transcripts were high in dormant conidia, and then decreased during isotropic and polarized growth (Figure 7A). The module was mostly enriched with genes involved in metabolism (secondary metabolism, fatty acid and carbohydrate metabolism), but other FunCat categories were also enriched, such as transcription and cellular transport (Figure 6). The darkgrey module was closely related to the turquoise module, and contained 41 genes. However, the FunCat enrichment did not show any significant hits $(p>0.05)$. 

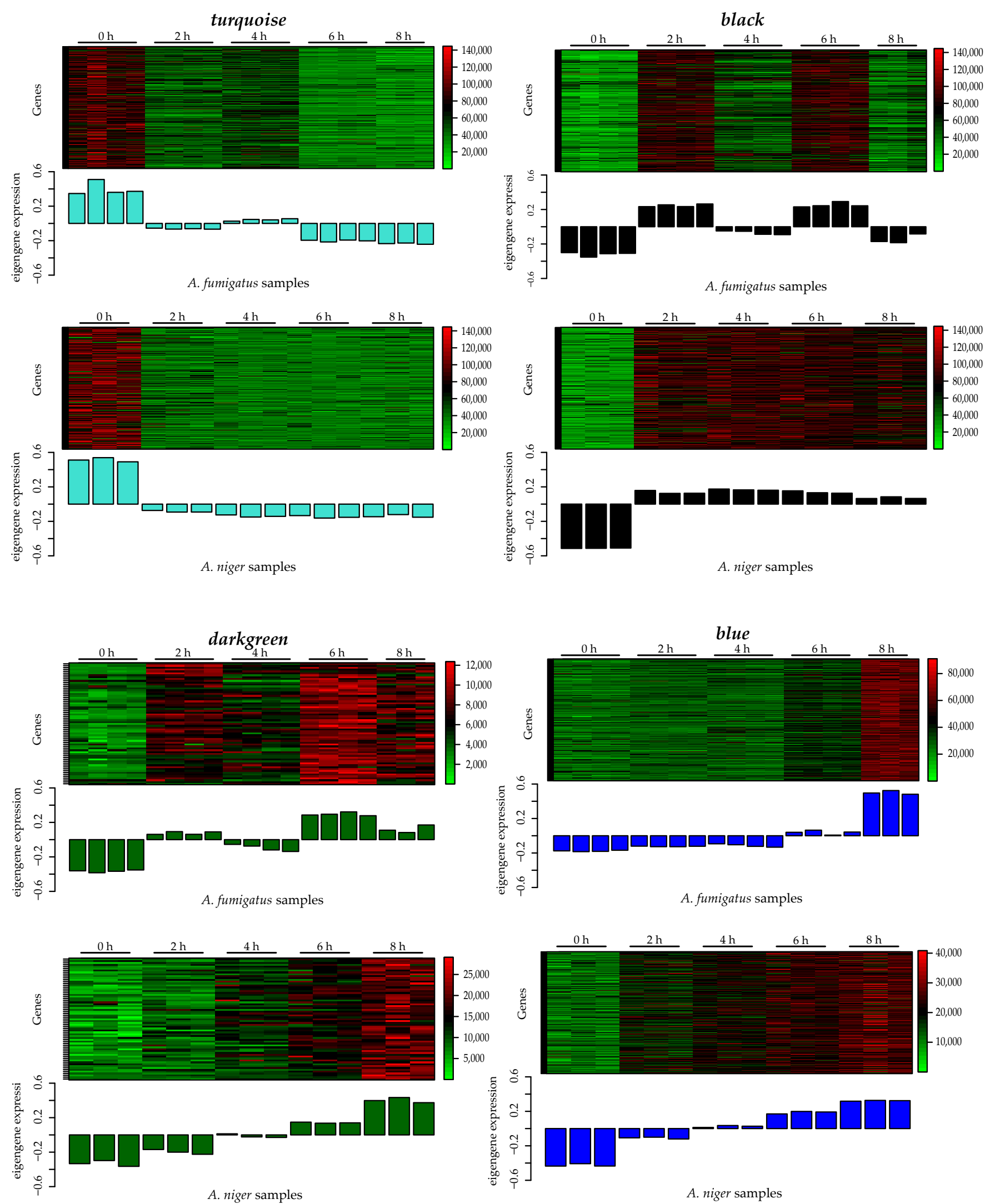

Figure 7. A-D. Heatmap of the gene expressions in each module (top) and expression levels of the corresponding module eigengene across the samples (bottom) for A. fumigatus and A. niger. The color bar shows the expression range of each module from the lowest to highest expression value. 


\subsubsection{Black}

The black module contained 308 genes that were mostly involved in protein synthesis (12), but categories associated with energy (02) were also enriched (Figure 4). Highly enriched categories were electron transport and membrane-associated energy conversion (02.11), ribosome biogenesis (12.01), ribosomal biogenesis (12.01.01), aminoacyl-tRNAsynthases (12.10), protein binding (16.01), and electron transport (20.01.15). Conidial outgrowth involves a fermentative metabolism, followed by a switch to respiration [33]. Concomitant with respiratory metabolism during the breaking of dormancy is protein synthesis, which is one of the earliest measurable biochemical changes during germination [54]. Transcriptomic and proteomic analyses have shown that the breaking of dormancy is characterized by an immediate onset of protein synthesis $[19,25,30]$. The transition from dormant conidia to isotropically expanding conidia and eventually germ tube formation involves biosynthetic machineries for which protein synthesis is required [13].

The gene expression patterns in the module were slightly different between A. fumigatus and A. niger (Figure 7B). In A. fumigatus, transcripts increased after $2 \mathrm{~h}$, then decreased slightly after $4 \mathrm{~h}$. This pattern was also observed during polarized growth; after $6 \mathrm{~h}$, transcripts increased, then decreased slightly after $8 \mathrm{~h}$. In A. niger, transcripts were low during the dormant phase, then increased and remained high during isotropic and polarized growth. These differences during isotropic and polarized growth between A. fumigatus and A. niger can also be seen in Figure 3, as the correlation scores are low.

The brown module was closely related to the black module, and contained 658 genes. The FunCat analysis mainly showed enriched categories associated with transcription (11) and protein synthesis (12), which were connected to the categories enriched in the black module (Table S2). Identical FunCat categories identified were ribosome biogenesis (12.01), ribosomal proteins (12.01.01), and translation (12.04). Various categories were associated with transcription (11), such as RNA synthesis (rRNA (11.02.01), tRNA (11.02.02) and mRNA (11.02.03)), RNA processing (rRNA (11.04.01), tRNA (11.04.02), and mRNA (11.04.03)), and RNA modification (rRNA (11.06.01) and tRNA (11.06.02)).

\subsubsection{Darkgreen}

The darkgreen module contained 65 genes, and was the second smallest module detected by the consensusWGCNA. The gene expression pattern in this module increased during isotropic and polarized growth (Figure 7C). Functional enrichment showed that only two categories were enriched in this module (Figure 4). The categories were conjunction of sulfate (01.02.03.04) associated with metabolism (01) and modification by ubiquitin-related proteins (14.07.07) associated with protein fate (14). The magenta module was closely related to the darkgreen and blue modules. This module contained 271 genes, and the FunCat analysis showed only three categories enriched: proteasomal degradation (14.13.01.01) and protein processing (14.07.11) associated with protein fate (14) and degradation of leucine (01.01.11.04.02) associated with metabolism (01).

\subsubsection{Blue}

The blue module contained 770 genes, and was the second largest module detected by the consensusWGCNA. This module was highly enriched in genes involved in polarized growth, together with genes involved in cell cycle and DNA processing (10) (Figure 7D, Figure 5).

Mitosis and Septum Formation

Highly enriched categories were mitotic cell cycle and cell cycle control (10.03.01), mitotic cell cycle (10.03.01.01), M phase (10.03.01.01.11), cytokinesis (cell division)/septum formation and hydrolysis (10.03.03), and nuclear migration (10.03.04.09). In A. fumigatus, the first mitosis was completed in $22 \%$ of the cells before polarized growth with the formation of a germ tube was initiated [27]. The number of nuclei increases during isotropic growth, and continues to increase during polarized growth [16]. Nuclear division is followed 
by the migration of nuclei into the elongating germ tube and septum formation. The septin $a s p C$ was found in the blue module, and plays a role in normal development and morphogenesis [55]. In $\Delta a s p C$ strains, germ tubes emerged early, and multiple germ tubes, together with early branching, were observed.

\section{Protein Processing}

Other highly enriched categories were protein targeting, sorting and translocation (14.04), protein processing (14.07.11), assembly of protein complexes (14.10), protein binding (16.01), structural protein binding (16.07), and enzymatic activity regulation/enzyme regulator (18.02.01).

\section{Onset of Polarization}

Highly enriched categories important for germ tube elongation were protein transport (20.01.10), vesicular transport (20.09.07), vesicle formation (20.09.07.25), cytoskeletondependent transport (20.09.14), cell growth/morphogenesis (40.01), cytoskeleton/structural proteins (42.04), intracellular transport vesicles (42.09), and budding, cell polarity, and filament formation (43.01.03.05). Polarized growth is characterized by the restriction of expansion of the cell wall on the swollen spore, which leads to a tubular outgrowth, the germ tube. Before this, a position on the plasma membrane has to be confined [22] for localized vesicle fusion and membrane extension. This will include orchestration of the cytoskeleton to traffic and deliver vesicles, which will lead to localized membrane expansion and cell wall deposition. This extension is the first appearance of germination, and the bulge will expand to a small tube, the germ tube, which extends by tip growth. During this stage, a septum is delineated at the base of the germ tube, and nuclei are transported into the growing cell. Several studies have identified a marked increase in the growth speed of the germ tube that will branch. In many cases, a second germ tube is formed on the swollen spore. Hyphae that grow at a higher velocity possess a so-called vesicle supply center [56], also designated as the Spitzenkörper (SPK) $[57,58]$. This is a dynamic structure containing different types of vesicles and cytoskeletal elements that maintain polarized growth. At early germination, similar organization is expected, but operating in a more diffuse way [59].

All of these processes were confirmed in the FunCat analysis, which showed categories growth/morphogenesis (40.01) and directional cell growth (morphogenesis) (40.01.03) enriched in the blue module. Additionally, the categories cytoskeleton/structural proteins (42.04), actin cytoskeleton (42.04.03), microtubule cytoskeleton (42.04.05), and bud/growth tip (42.29) were enriched. Microtubules are primarily responsible for the transport of secretory vesicles to the location of localized expansion and in fully growing hyphae, the SPK, while actin filaments primarily control the organization of vesicles and facilitate transport/delivery to the plasma membrane [60]. Enriched FunCat categories associated with transport were protein transport (20.01.10), vesicular transport (20.09.07), vesicle formation (20.09.07.25), tubulin-dependent transport (20.09.14.01), actin-dependent transport (20.09.14.02), exocytosis (20.09.16.09.03), and receptor-mediated endocytosis (20.09.18.09.01), among others (Figure 7). Several genes encoding secretion-related GTPases and interacting proteins were present in the blue module, such as An01g04040/Afu1g04940, An01g06060/Afu1g02190, An08g03690/Afu1g11730, An14g00010/Afu4g04810, and An18g 02490/Afu5g11900 [40] (Table 1). In A. nidulans, homologs of An14g00010/Afu4g04810 (RabD) and An01g06060/Afu1g02190 (RabE) were detected in the SPK [61]. Microtubule and actin-dependent transport involves the trafficking and delivery of vesicles to the plasma membrane, which will lead to localized expansion of the cell membrane. Other proteins are also involved in the distribution of vesicles to their final destination. 
Table 1. Genes involved in biological processes associated with polarized growth.

\begin{tabular}{|c|c|c|c|}
\hline Biological Process & A. niger & A. fumigatus & Description \\
\hline \multirow{6}{*}{$\begin{array}{l}\text { Secretion-related GTPases } \\
\text { and interacting proteins }\end{array}$} & sarA/An01g04040 & Afu1g04940 & $\begin{array}{l}\text { Small GTPase of the ARF family, likely a component of } \\
\text { COPII coat of transport vesicles }\end{array}$ \\
\hline & An01g06060 & rab11/Afu1g02190 & Ras GTPase \\
\hline & An08g03690 & Afu1g11730 & Ortholog(s) have GTPase activity and role in Golgi to \\
\hline & $\operatorname{srg} A / \operatorname{An} 14 \mathrm{~g} 00010$ & srgA/Afu4g04810 & Putative Rab GTPase \\
\hline & An02g07780 & Afu3g12080 & $\begin{array}{c}\text { Ortholog(s) have GTPase activity, enzyme activator activity, } \\
\text { mRNA binding activity }\end{array}$ \\
\hline & geaA/An18g02490 & Afu5g11900 & Putative guanine nucleotide exchange factor \\
\hline \multirow{5}{*}{ Exocyst } & An08g05570 & Afu1g12790 & $\begin{array}{l}\text { Ortholog(s) have a role in golgi to plasma membrane } \\
\text { transport, endoplasmic reticulum inheritance, } \\
\text { establishment or maintenance of cell polarity, exocyst } \\
\text { assembly }\end{array}$ \\
\hline & An08g07370 & Afu6g11370 & $\begin{array}{l}\text { Ortholog(s) have role in golgi to plasma membrane } \\
\text { transport, exocyst assembly, exocyst localization }\end{array}$ \\
\hline & An14g00010 & $\operatorname{srg} A / A f u 4 g 04810$ & Putative Rab GTPase \\
\hline & cftA/An02g14200 & cdc42/Afu2g05740 & Rho GTPase \\
\hline & rhoA/An18g05980 & rho1/Afu6g06900 & Ras GTPase \\
\hline \multirow{5}{*}{$\begin{array}{l}\text { SNAREs and SNARE } \\
\text { interactions }\end{array}$} & An02g01580 & sec17/Afu2g12870 & Putative vesicular fusion protein \\
\hline & An04g07020 & Afu4g10040 & Ortholog(s) have golgi cisterna, endosome localization \\
\hline & An07g02170 & Afu7g05735 & Putative v-SNARE \\
\hline & An07g09960 & Afu1g07420 & Putative v-SNARE \\
\hline & An15g01380 & Afu6g04150 & $\begin{array}{l}\text { Ortholog(s) have SNAP receptor activity and a role in ER } \\
\text { to golgi vesicle-mediated transport, retrograde } \\
\text { vesicle-mediated transport, golgi to ER, vesicle fusion with } \\
\text { golgi apparatus }\end{array}$ \\
\hline \multirow{9}{*}{ Cell wall biosynthesis } & $c f c D / A n 01 g 05360$ & Afu1g02800 & \multirow{9}{*}{$\begin{array}{c}\text { Putative chitinase } \\
\text { Putative 1,3-beta-glucanosyltransferase } \\
\text { Ortholog(s) have role in (1->6)-beta-D-glucan biosynthetic } \\
\text { process } \\
\text { Putative cell wall glucanase } \\
\text { GPI-anchored 1,3-beta-glucanosyltransferase } \\
\text { Chitin synthase } \\
\text { Alpha-amylase } \\
\text { Putative beta-glucanase } \\
\text { Putative cell wall glucanase }\end{array}$} \\
\hline & An03g06220 & gel5/Afu8g02130 & \\
\hline & An05g00130 & Afu2g07590 & \\
\hline & $\operatorname{crhB} / \mathrm{An} 07 \mathrm{~g} 07530$ & crh2/Afu2g03120 & \\
\hline & An08g07350 & gel2/Afu6g11390 & \\
\hline & chsD/An09g02290 & chsF/Afu8g05630 & \\
\hline & agt $A /$ An09g03100 & amyA/Afu3g00900 & \\
\hline & An16g02850 & crh3/Afu3g09250 & \\
\hline & An16g07040 & $b \operatorname{tg} E / \mathrm{Afu} 8 \mathrm{~g} 05610$ & \\
\hline Cell end markers & An18g04780 & Afu1g06090 & $\begin{array}{l}\text { Ortholog(s) have a role in apical protein localization, } \\
\text { regulation of cell shape and cell septum, plasma membrane } \\
\text { of cell tip, spitzenkorper localization }\end{array}$ \\
\hline \multirow{3}{*}{ Cdc42 complex } & cftA/An02g14200 & $\bmod A / \mathrm{Afu} 2 \mathrm{~g} 05740$ & \multirow{3}{*}{$\begin{array}{c}\text { Rho GTPase } \\
\text { Ortholog(s) have Rho guanyl-nucleotide exchange factor } \\
\text { activity } \\
\text { Rho GTPase involved in regulation of cell polarity }\end{array}$} \\
\hline & cdc24/An04g05150 & $c d c 24 / \mathrm{Afu} 4 \mathrm{~g} 11450$ & \\
\hline & racA/An11g10030 & $\mathrm{racA} / \mathrm{Afu} 3 \mathrm{~g} 06300$ & \\
\hline Polarisome & spaA/An07g08290 & Afu2g03710 & $\begin{array}{l}\text { Ortholog(s) have role in establishment of cell polarity, } \\
\text { establishment, or maintenance of cell polarity, hyphal } \\
\text { growth and hyphal tip polarisome localization }\end{array}$ \\
\hline \multirow{4}{*}{ Arp 2/3 complex } & An08g06400 & Afu1g13330 & \multirow{4}{*}{$\begin{array}{c}\text { Ortholog(s) have actin filament binding activity, role in } \\
\text { Arp2/3 complex-mediated actin nucleation, endocytosis, } \\
\text { spore germination and Arp2/3 protein complex, actin } \\
\text { cortical patch localization } \\
\text { Ortholog(s) have actin filament binding activity, role in } \\
\text { Arp2/3 complex-mediated actin nucleation and Arp2/3 } \\
\text { protein complex localization } \\
\text { Ortholog(s) have actin filament binding, molecular adaptor } \\
\text { activity, role in Arp } 2 / 3 \text { complex-mediated actin nucleation, } \\
\text { actin cortical patch organization, spore germination and } \\
\text { Arp2/3 protein complex localization } \\
\text { Ortholog(s) have actin filament binding activity }\end{array}$} \\
\hline & An01g05510 & Afu1g02670 & \\
\hline & An12g08380 & Afu6g02370 & \\
\hline & An16g01570 & Afu5g01860 & \\
\hline
\end{tabular}

In S. cerevisiae, members of the Cdc42 complex are Cdc42, Cdc24, Bem1, Cla4, and Ste12. In the blue module, homologs of the Rho-type GTPase $c d c 42(c f t A)$ and its guanidine exchange factor (GEF) $c d c 24$ (An04g05150) were present, together with Rho-type GTPase $\operatorname{rac} A(\operatorname{rac} A)$ (Table 1$)$. These homologues have been studied in $A$. nidulans (modA and $\operatorname{rac} A$ ) 
and Neurospora crassa (CDC-42 and RAC-1) [62,63]. In A. nidulans, ModA (Cdc42) and RacA (Rac1) share an overlapping function required for polarity establishment. The double knockout $\Delta c d c 42 \Delta r a c 1$ appeared to be synthetically lethal. Additionally, GEF Cdc42 was required for the establishment of hyphal polarity, and localized to hyphal tips [64]. In N. crassa, the spatial distribution of the two Rho-type GTPases Cdc42 and Rac1 changes during the various differentiation stages. Before the breakage of symmetry in conidia, the localization and localized activation of Cdc42 and its GEF Cdc24 occur. After emergence of the germ tube, Rac1 is recruited at the developing tip. Together, Cdc42 and Rac1 regulate the negative chemotropism displayed during germ tube formation.

\section{Establishment of Polarized Growth, Hyphal Elongation}

Cell wall expansion is necessary for every expansion of the cell, being isotropic or polarized. Cell wall biosynthesis genes were also identified, belonging to different glycoside hydrolase and glycoside transferase families, such as GH13 (An09g03100/Afu3g00900), GH16 (An07g07530/Afu2g03120, An16g02850/Afu3g09250), GH17 (An16g07040/Afu8g05610), GH18 (An01g05360/Afu1g02800), GH72 (An03g06220/Afu8g02130, An08g07350/Afu6g 11390), and GT2 (An09g02290/Afu8g05630) (CAZy. Available online: http: / / www.cazy. org / , accessed on 18/03/2021). Another identified cell wall biosynthesis gene (An05g00130/ Afu2g07590) has a predicted role in the (1->6)-beta-D-glucan biosynthetic process. Some of the cell wall biosynthesis genes are glycosylphosphatidylinositol (GPI) anchored enzymes, and one is a chitin synthase. Chitin synthases and glucan synthase complexes are transported in vesicles and fuse with the plasma membrane, where the enzymes are inserted to synthesize chitin and glucan polysaccharides [65]. The glycoproteins are also transported through the secretory pathway to the growth tip and, after exocytosis, remain attached to the plasma membrane by the GPI anchor.

The SPK is vital for polarity maintenance during hyphal tip extension. The polarity maintenance machinery consists of cytoskeleton components, such as microtubules and actin filaments, and several groups of proteins termed the Cdc42 complex, polarisome, and Arp2/3 complex. These complexes are located in the growing tip area close to the apical plasma membrane [66]. Microtubules regulate the position of proteins, such as cell end markers. The cell end marker teaR (An18g04780) was found in the blue module. In A. nidulans, TeaR is anchored to the plasma membrane, and directly interacts with TeaA, another cell end marker [67]. This interaction at the apical membrane is important for the recruitment of additional downstream components, including the formin SepA, which is involved in the polymerization of actin filaments for targeted vesicle transport [68].

Components of the polarisome act downstream of the Cdc42 complex, and are conserved from yeast to filamentous fungi [69]. Only one of three components of the A. niger polarisome was found in the blue module, spaA (Table 1). SpaA localizes exclusively at the hyphal tip and plays a role in polarity maintenance [70]. The Arp2/3 complex is another group of proteins involved in polarity maintenance, endocytosis, and actin polymerization. The complex includes Arp2, Arp3, Arc40, Arc35, Arc18, Arc19, and Arc15 in S. cerevisiae [71]. Several Arp2/3 homologs were identified in the blue module, such as Arp2 (An08g06400), Arc35 (An01g05510), Arc19 (An12g08380), and Arc18 (An16g01570) (Table 1).

Vesicles transport cell wall-modifying enzymes, substrates, and the cell membrane required for expansion to the growing tip. The exocyst is a protein complex involved in vesicle docking and fusion to the plasma membrane, and was originally identified in the budding yeast $S$. cerevisiae [72,73]. This complex consists of eight proteins, Sec3, Sec5, Sec6, Sec8, Sec10, Sec15, Exo70, and Exo84, and interacts with Rho-type GTPases Cdc42, Rho1, and Rho3, as well as with Rab GTPase Sec4, which is present on the membrane surface of vesicles [72]. In the blue module, we identified homologs of Sec5 (An08g05570/Afu1g12790), Exo84 (An08g07370/Afu6g11370), Sec4 (An14g00010/Afu4g04810), and Rho1 (An18g05980/ Afu6g06900) (Table 1). In N. crassa, a mutation in the Sec5 homolog resulted in swollen conidia and altered hyphal growth, indicating its role in polarity establishment and maintenance [74]. The Rab GTPase SrgA (Sec4) was involved in vesicle secretion and filamentous 
growth in A. niger $[75,76]$. Another group of proteins that facilitate vesicle docking and fusion to the plasma membrane are soluble $\mathrm{N}$-ethylmaleimide-sensitive fusion protein (NSF) attachment protein receptors (SNAREs). At the hyphal tip, SNAREs present on the target membrane (t-SNAREs) pair with SNAREs present on the vesicles (v-SNAREs) to mediated the fusion of membranes [77]. Several SNAREs and SNARE interacting genes were identified in the blue module, such as An02g01580/Afu2g12870, An04g07020/Afu4g10040, An07g02170/Afu7g05735, An07g09960/Afu1g07420, and An15g01380/Afu6g04150 [40] (Table 1). Endocytosis is the reverse process, characterized by the formation of membrane vesicles that are invaginated and included in the vesicle transport routings. It occurs in germinating spores $[78,79]$ at the onset of polarization. In the case of growing hyphae, endocytotic vesicles are internalized most strongly in a collar-like region behind the hyphal apex, and fuse with early endosomes [80], which participate in tip growth.

\section{Discussion}

The process of germination of conidia involves the transition from a dormant, stressresistant cell with low metabolic activity into a vegetatively active fungal hypha. In this study, the transcriptomic changes are studied throughout this transition. In this crossplatform, cross-species comparative analysis, we studied conidial germination of two Aspergillus species: $A$. niger and A. fumigatus, enabling us to integrate the transcriptional expression of two related species and two different techniques and providing biological insights in germination of conidia.

Firstly, to perform this cross-platform, cross-species comparative analysis, we used the following bioinformatic approach: (i) a selection of 6598 ortholog genes was necessary to integrate the two datasets, which enclosed nearly $50 \%$ of the $A$. niger genes and over $50 \%$ of the A. fumigatus genes. A comparison of 34 ascomycete genomes, including 19 Aspergillus species, showed that $\sim 8500$ genes were pan-fungal, which was inferred from MCL clustering of proteins [81]. For our analysis, the two datasets needed to be integrated one to one based on orthologous genes. Finding best hits using the RBH method involved sorting the results from lowest to highest e-values, then, from highest to lowest bit-scores. The first hit within the sorting would be the best hit. If the next best hit had the same bit-score and e-value, there would be more than one best hit (co-orthologs). In our study, the co-orthologs were discarded, which may be the cause of the difference in identified orthologous genes, together with the different methods used in both studies. (ii) Normalization of the intensities was done, as both techniques have different expression values, i.e., RNA-Seq counts and microarray fluorescence intensities. (iii) Expression patterns during germination stages were compared. Presently, RNA-Seq has emerged as the technology of choice for gene expression profiling [82]. RNA-Seq is able to detect novel transcripts, map exon/intron boundaries (if full genomes are available), and reveal splice variants. Additionally, RNA-Seq provides more resolution to detect extreme expression values, such as genes with very low transcript counts and genes with extremely high transcript counts [83]. However, microarrays are reliable, and the variety of datasets publicly available offers an exceptional opportunity to perform cost-effective and insightful comparisons.

Secondly, the cross-platform, cross-species analysis confirmed the occurrence of conserved, generic, and functionally important biological processes during germination, which are independent of a single technology. This is more interesting, as A. fumigatus belongs to subgenus Fumigati, section Fumigati and A. niger to subgenus Circumdati, section Nigri [1]. A phylogenetic analysis showed that section Nigri is more closely related to subgenus Nidulantes than to Circumdati [84]. However, based on phenotypic and extrolite data and their phylogenetic analysis, Houbraken et al. [1] maintained section Nigri in subgenus Circumdati until more data supporting the analysis of Steenwyk et al. [84] become available. Additionally, experimental conditions of both studies were different, such as the pre-culture medium and germination medium. Nutritional environment during sporulation, as well as during germination, affects the rate of the breaking of dormancy and growth in $A$. fumigatus [85]. A. fumigatus strains were cultivated on Sabouraud agar slants (dextrose 
$40 \mathrm{~g} / \mathrm{L}$, peptone $10 \mathrm{~g} / \mathrm{L}$, agar $20 \mathrm{~g} / \mathrm{L}, \mathrm{pH}=5.6)$ for five days at $30^{\circ} \mathrm{C}$, and $A$. niger was cultivated on complete medium (CM) (1.5\% agar, $6.0 \mathrm{~g} \mathrm{NaNO} 3,1.5 \mathrm{~g} \mathrm{KH} 2 \mathrm{PO} 4,0.5 \mathrm{~g} \mathrm{KCl}$, $0.5 \mathrm{~g} \mathrm{MgSO} 4,4.5 \mathrm{~g}$ D-glucose, $0.5 \%$ casamino acids, $1 \%$ yeast extract, and $200 \mu \mathrm{L}$ trace elements per liter) for 12 days at $25^{\circ} \mathrm{C}$. RNA was extracted after growth in liquid RPMI 1640 (Gibco ${ }^{\circledR}$ life technologies) and liquid CM for A. fumigatus and A. niger, respectively. Morphological changes during germination, such as swelling and germ tube formation, were observed at similar time points, despite different pre-culture and germination conditions. The bioinformatic analysis was focused on identifying biological similarities associated with germination between $A$. fumigatus and A. niger. The different experimental setup, together with differences in RNA extraction and library preparation of the original studies, will doubtlessly cause biological differences. By integrating the expression data one on one based on orthologous gene pairs and constructing a consensus gene co-expression network, we excluded the biological differences and identified biological similarities.

A consensusWGCNA was performed to examine the transcriptomic similarities between germinating $A$. fumigatus and $A$. niger conidia. Recently, numerous studies have been published using WGCNA to identify co-expressed genes related to an external trait in various fields [86-91]. In this study, we detected co-expressed consensus modules between A. fumigatus and $A$. niger and investigated the module relationships with the different morphological phases in germination. Five co-expression modules associated with either the dormant, isotropic, or polarized phase were identified. Genes within each module were considered to be related to each other in function, or could work cooperatively in specific molecular processes. Functional enrichment on the larger modules, such as the black and blue modules, adequately showed clustering of genes involved in similar or identical pathways. However, the midnightblue module (130 genes) did not show enrichment of a functional category, which could be because of the poorly characterized A. fumigatus and $A$. niger genomes. The module contained $\sim 40$ genes without annotation and almost all other annotations were putative. Additionally, in both studies, RNA was extracted from a population of germinating conidia. Conidial germination was relatively synchronous when appropriate exogenous nutrients were present [16]. However, in the transition from dormant conidia to swelling to germ tube elongation, conidial swelling is the middle phase, and therefore difficult to characterize when analyzing the transcriptome of a population of conidia.

The gene expression pattern in the black module, associated with protein synthesis, showed an increase after $2 \mathrm{~h}$. Lamarre et al. showed similar results in A. fumigatus; 30 min post-dormancy transcripts were identified from protein synthesis, carbohydrate metabolism, protein complex assembly, and RNA binding protein [25]. This was recently confirmed by Danion et al., where germination was induced by the presence of nutrients, such as carbon and nitrogen, without the novo RNA transcription [16]. The proteome profile of $A$. flavus at the conidial germination stage resulted in overrepresented protein synthesis categories [26]. The gene expression pattern in the blue module, associated with polarized growth, showed a strong increase after $6 \mathrm{~h}$. In several Aspergillus spp, germ tube formation was observed after 6-8 h of germination [18,23-26]. Our co-expression network analysis using only A. fumigatus RNA-Seq data also identified a module associated with the onset of polarized growth. However, the consensus co-expression analysis performed in this study identified detailed functional categories associated with the tip growth and formation of an SPK [65,92-94]. Oda et al. found that transcript levels were steady for genes encoding the Cdc42 complex and polarisome during the switch from isotropic to polarized growth, such as modA (An02g14200), cdc24 (An04g05150), and spaA (An07g08290) [24], whereas our data showed a strong increase of these transcripts in the blue module in both $A$. fumigatus and $A$. niger. Besides the modules significantly correlated to a trait, closely related modules, termed meta-modules, were analyzed, as these modules may be biologically similar [53]. The higher-level cluster of the black and brown module showed a relationship between the gene transcripts in each module. The black module was highly enriched 
with protein synthesis genes, and, similarly, the brown module was highly enriched with transcription and protein synthesis genes.

Thirdly, these insights enable us to define processes that might be used as therapeutic targets to suppress antifungal development in the lungs. Antifungals targeting germination processes would only work as prophylaxis, as only established infections consisting of hyphae will be diagnosed and treated. Conidia swelling inside causes the lungs to need to remodel their cell wall, therefore, the enzymatic activity of glycoside hydrolases and glycoside transferases may be potential targets for prophylaxis. Before germ tube formation, a position on the plasma membrane has to be confined for localized vesicle fusion and membrane extension. This ergosterol-enriched cap in germinating conidia at the site of germ tube formation could be an attractive target, as the prevention of this ergosterol patch may disturb the localized transport to the site of polarization. Processes important for germ tube formation and tip elongation, such as vesicle transport and exocytosis/endocytosis, might also be feasible as antifungal development targets.

\section{Conclusions}

In this study, we demonstrated the possibility for comparative analysis between Aspergillus spp using two different transcriptional profiling platforms, which introduces the opportunity to perform cost-effective insightful comparisons. The consensus gene coexpression network detected modules associated with transcription and protein synthesis and polarized growth. Through cross-platform, cross-species comparative analysis, we were able to identify biologically meaningful modules shared by A. fumigatus and A. niger, which underscores the potential of this approach.

Supplementary Materials: The following are available online at https:/ / www.mdpi.com/article/ 10.3390/jof7040270/s1, Figure S1: Expression profiles of the A. fumigatus and A. niger datasets after normalization without outliers removed. Figure S2: Module-trait relationships. Figure S3: The correlation of the consensus modules with the external trait. Table S1: Command lines. Table S2: Functional enrichment analysis.

Author Contributions: Conceptualization, T.J.H.B. and J.D.; methodology, T.J.H.B. and J.P.M.C.; formal analysis, T.J.H.B. and J.P.M.C.; writing—original draft preparation, T.J.H.B.; writing-review and editing, all authors; visualization, T.J.H.B.; supervision, P.E.V., J.D. and W.J.G.M. All authors have read and agreed to the published version of the manuscript.

Funding: This research received no external funding.

Institutional Review Board Statement: Not applicable.

Informed Consent Statement: Not applicable.

Data Availability Statement: The raw data were accessed through the NCBI Gene Expression Omnibus accession number GSE36439 (www.ncbi.nlm.nih.gov/geo/, accessed on 24 March 2020) and the NCBI Sequence Read Archive accession number PRJNA408076 (https:/ /www.ncbi.nlm.nih. gov /sra, accessed on 24 March 2020).

Acknowledgments: We kindly thank Martijn Huijnen, Arthur Ram, and Sjoerd Seekles for helpful comments on the data analysis.

Conflicts of Interest: We report no conflict, except for P.E.V., who has received research grants from Gilead Sciences, Pfizer, MSD, F2G, and Mundipharma outside of the submitted work, is a speaker for Gilead Sciences and MSD, and is on the advisory boards for Pfizer, MSD, and F2G.

\section{References}

1. Houbraken, J.; Kocsubé, S.; Visagie, C.; Yilmaz, N.; Wang, X.-C.; Meijer, M.; Kraak, B.; Hubka, V.; Bensch, K.; Samson, R.; et al. Classification of Aspergillus, Penicillium, Talaromyces and related genera (Eurotiales): An overview of families, genera, subgenera, sections, series and species. Stud. Mycol. 2020, 95, 5-169. [CrossRef] [PubMed]

2. Shinn, E.A.; Smith, G.W.; Prospero, J.M.; Betzer, P.; Hayes, M.L.; Garrison, V.; Barber, R.T. African dust and the demise of Caribbean Coral Reefs. Geophys. Res. Lett. 2000, 27, 3029-3032. [CrossRef] 
3. Silva, J.J.; Bertoldo, R.; Fungaro, M.H.P.; Massi, F.P.; Taniwaki, M.H.; Sant'Ana, A.S.; Iamanaka, B.T. Black aspergilli in Brazilian onions: From field to market. Int. J. Food Microbiol. 2021, 337, 108958. [CrossRef] [PubMed]

4. Golan, J.J.; Pringle, A. Long-Distance Dispersal of Fungi. In the Fungal Kingdom; ASM Press: Washington, DC, USA, 2017; pp. 309-333.

5. Van De Veerdonk, F.L.; Gresnigt, M.S.; Romani, L.; Netea, M.G.; Latgé, J.-P. Aspergillus fumigatus morphology and dynamic host interactions. Nat. Rev. Genet. 2017, 15, 661-674. [CrossRef] [PubMed]

6. Carrion, S.D.J.; Leal, S.M.; Ghannoum, M.A.; Aimanianda, V.; Latgé, J.-P.; Pearlman, E. The RodA Hydrophobin on Aspergillus fumigatus Spores Masks Dectin-1- and Dectin-2-Dependent Responses and Enhances Fungal Survival In Vivo. J. Immunol. 2013, 191, 2581-2588. [CrossRef] [PubMed]

7. Aimanianda, V.; Bayry, J.; Bozza, S.; Kniemeyer, O.; Perruccio, K.; Elluru, S.R.; Clavaud, C.; Paris, S.; Brakhage, A.A.; Kaveri, S.V.; et al. Surface hydrophobin prevents immune recognition of airborne fungal spores. Nat. Cell Biol. 2009, 460, 1117-1121. [CrossRef]

8. Brown, G.D.; Denning, D.W.; Gow, N.A.R.; Levitz, S.M.; Netea, M.G.; White, T.C. Hidden Killers: Human Fungal Infections. Sci. Transl. Med. 2012, 4, 165rv13. [CrossRef]

9. Hayes, G.E.; Novak-Frazer, L. Chronic Pulmonary Aspergillosis-Where Are We? and Where Are We Going? J. Fungi 2016, 2, 18. [CrossRef]

10. Verweij, P.E.; Rijnders, B.J.A.; Brüggemann, R.J.M.; Azoulay, E.; Bassetti, M.; Blot, S.; Calandra, T.; Clancy, C.J.; Cornely, O.A.; Chiller, T.; et al. Review of influenza-associated pulmonary aspergillosis in ICU patients and proposal for a case definition: An expert opinion. Intensiv. Care Med. 2020, 46, 1524-1535. [CrossRef]

11. Koehler, P.; Bassetti, M.; Chakrabarti, A.; Chen, A.S.C.; Colombo, A.L.; Hoenigl, M.; Klimko, N.; Lass-Flörl, C.; Oladele, O.R.; Vinh, D.C.; et al. Defining and managing COVID-19-associated pulmonary aspergillosis: The 2020 ECMM/ISHAM consensus criteria for research and clinical guidance. Lancet Infect. Dis. 2020. [CrossRef]

12. Bertuzzi, M.; Hayes, G.E.; Icheoku, U.J.; Van Rhijn, N.; Denning, D.W.; Osherov, N.; Bignell, E.M. Anti-Aspergillus Activities of the Respiratory Epithelium in Health and Disease. J. Fungi 2018, 4, 8. [CrossRef] [PubMed]

13. Baltussen, T.J.H.; Zoll, J.; Verweij, P.E.; Melchers, W.J.G. Molecular Mechanisms of Conidial Germination in Aspergillus spp. Microbiol. Mol. Biol. Rev. 2019, 84, 84. [CrossRef] [PubMed]

14. Krijgsheld, P.; Bleichrodt, R.; van Veluw, G.; Wang, F.; Müller, W.; Dijksterhuis, J.; Wösten, H. Development in Aspergillus. Stud. Mycol. 2013, 74, 1-29. [CrossRef]

15. Hayer, K.; Stratford, M.; Archer, D.B. Structural Features of Sugars That Trigger or Support Conidial Germination in the Filamentous Fungus Aspergillus niger. Appl. Environ. Microbiol. 2013, 79, 6924-6931. [CrossRef] [PubMed]

16. Danion, F.; Van Van Rhijn, N.; Dufour, A.C.; Legendre, R.; Sismeiro, O.; Varet, H.; Olivo-Marin, J.-C.; Mouyna, I.; Chamilos, G.; Bromley, M.; et al. Aspergillus fumigatus, One Uninucleate Species with Disparate Offspring. J. Fungi 2021, 7, 30. [CrossRef] [PubMed]

17. Hayer, K.; Stratford, M.; Archer, D.B. Germination of Aspergillus niger Conidia Is Triggered by Nitrogen Compounds Related to 1-Amino Acids. Appl. Environ. Microbiol. 2014, 80, 6046-6053. [CrossRef]

18. Van Leeuwen, M.; Krijgsheld, P.; Bleichrodt, R.; Menke, H.; Stam, H.; Stark, J.; Wösten, H.; Dijksterhuis, J. Germination of conidia of Aspergillus niger is accompanied by major changes in RNA profiles. Stud. Mycol. 2013, 74, 59-70. [CrossRef]

19. Novodvorska, M.; Hayer, K.; Pullan, S.T.; Wilson, R.; Blythe, M.J.; Stam, H.; Stratford, M.; Archer, D.B. Trancriptional landscape of Aspergillus niger at breaking of conidial dormancy revealed by RNA-sequencing. BMC Genom. 2013, 14, 246. [CrossRef]

20. Van Leeuwen, M.; Krijgsheld, P.; Wyatt, T.; Golovina, E.; Menke, H.; Dekker, A.; Stark, J.; Stam, H.; Bleichrodt, R.; Wösten, H.; et al. The effect of natamycin on the transcriptome of conidia of Aspergillus niger. Stud. Mycol. 2013, 74, 71-85. [CrossRef]

21. Van Leeuwen, M.R.; Van Doorn, T.M.; Golovina, E.A.; Stark, J.; Dijksterhuis, J. Water- and Air-Distributed Conidia Differ in Sterol Content and Cytoplasmic Microviscosity. Appl. Environ. Microbiol. 2009, 76, 366-369. [CrossRef]

22. Van Leeuwen, M.; Smant, W.; De Boer, W.; Dijksterhuis, J. Filipin is a reliable in situ marker of ergosterol in the plasma membrane of germinating conidia (spores) of Penicillium discolor and stains intensively at the site of germ tube formation. J. Microbiol. Methods 2008, 74, 64-73. [CrossRef]

23. Baltussen, T.J.; Coolen, J.P.; Zoll, J.; Verweij, P.E.; Melchers, W.J. Gene co-expression analysis identifies gene clusters associated with isotropic and polarized growth in Aspergillus fumigatus conidia. Fungal Genet. Biol. 2018, 116, 62-72. [CrossRef]

24. Oda, K.; Bignell, E.; Kang, S.E.; Momany, M. Transcript levels of theAspergillus fumigatusCdc42 module, polarisome, and septin genes show little change from dormancy to polarity establishment. Med Mycol. 2016, 55, 445-452. [CrossRef]

25. Lamarre, C.; Sokol, S.; Debeaupuis, J.-P.; Henry, C.; Lacroix, C.; Glaser, P.; Coppée, J.-Y.; François, J.-M.; Latgé, J.-P. Transcriptomic analysis of the exit from dormancy of Aspergillus fumigatus conidia. BMC Genom. 2008, 9, 417. [CrossRef]

26. Tiwari, S.; Thakur, R.; Goel, G.; Shankar, J. Nano-LC-Q-TOF Analysis of Proteome Revealed Germination of Aspergillus flavus Conidia is Accompanied by MAPK Signalling and Cell Wall Modulation. Mycopathologia 2016, 181, 769-786. [CrossRef]

27. Momany, M.; Taylor, I. Landmarks in the early duplication cycles of Aspergillus fumigatus and Aspergillus nidulans: Polarity, germ tube emergence and septation. Microbiology 2000, 146, 3279-3284. [CrossRef]

28. Cagas, S.E.; Jain, M.R.; Li, H.; Perlin, D.S. The Proteomic Signature of Aspergillus fumigatus During Early Development. Mol. Cell. Proteom. 2011, 10. [CrossRef] [PubMed] 
29. Suh, M.-J.; Fedorova, N.D.; Cagas, E.S.; Hastings, S.; Fleischmann, R.D.; Peterson, S.N.; Perlin, D.S.; Nierman, W.C.; Pieper, R.; Momany, M. Development stage-specific proteomic profiling uncovers small, lineage specific proteins most abundant in the Aspergillus Fumigatus conidial proteome. Proteome Sci. 2012, 10, 30. [CrossRef] [PubMed]

30. Teutschbein, J.; Albrecht, D.; Pötsch, M.; Guthke, R.; Aimanianda, V.; Clavaud, C.; Latgé, J.-P.; Brakhage, A.A.; Kniemeyer, O. Proteome Profiling and Functional Classification of Intracellular Proteins from Conidia of the Human-Pathogenic MoldAspergillus fumigatus. J. Proteome Res. 2010, 9, 3427-3442. [CrossRef] [PubMed]

31. Kubitschek-Barreira, P.H.; Curty, N.; Neves, G.W.; Gil, C.; Lopes-Bezerra, L.M. Differential proteomic analysis of Aspergillus fumigatus morphotypes reveals putative drug targets. J. Proteom. 2013, 78, 522-534. [CrossRef] [PubMed]

32. Thakur, R.; Shankar, J. Proteome Profile of Aspergillus terreus Conidia at Germinating Stage: Identification of Probable Virulent Factors and Enzymes from Mycotoxin Pathways. Mycopathologia 2017, 182, 771-784. [CrossRef] [PubMed]

33. Novodvorska, M.; Stratford, M.; Blythe, M.J.; Wilson, R.; Beniston, R.G.; Archer, D.B. Metabolic activity in dormant conidia of Aspergillus niger and developmental changes during conidial outgrowth. Fungal Genet. Biol. 2016, 94, 23-31. [CrossRef] [PubMed]

34. Hagiwara, D.; Takahashi, H.; Kusuya, Y.; Kawamoto, S.; Kamei, K.; Gonoi, T. Comparative transcriptome analysis revealing dormant conidia and germination associated genes in Aspergillus species: An essential role for AtfA in conidial dormancy. BMC Genom. 2016, 17, 1-18. [CrossRef] [PubMed]

35. Breakspear, A.; Momany, M. Aspergillus nidulans Conidiation Genes dewA, fluG, and stuA Are Differentially Regulated in Early Vegetative Growth. Eukaryot. Cell 2007, 6, 1697-1700. [CrossRef] [PubMed]

36. Asif, A.R.; Oellerich, M.; Amstrong, V.W.; Riemenschneider, B.; Monod, M.; Reichard, U. Proteome of Conidial Surface Associated Proteins of Aspergillus fumigatus Reflecting Potential Vaccine Candidates and Allergens. J. Proteome Res. 2006, 5, 954-962. [CrossRef] [PubMed]

37. Bos, C.J.; Debets, A.J.M.; Swart, K.; Huybers, A.; Kobus, G.; Slakhorst, S.M. Genetic analysis and the construction of master strains for assignment of genes to six linkage groups in Aspergillus niger. Curr. Genet. 1988, 14, 437-443. [CrossRef] [PubMed]

38. Overbeek, R.; Fonstein, M.; D'Souza, M.; Pusch, G.D.; Maltsev, N. The use of gene clusters to infer functional coupling. Proc. Natl. Acad. Sci. USA 1999, 96, 2896-2901. [CrossRef]

39. Nierman, W.C.; Pain, A.; Anderson, M.J.; Wortman, J.R.; Kim, H.S.; Arroyo, J.; Berriman, M.; Abe, K.; Archer, D.B.; Bermejo, C.; et al. Genomic sequence of the pathogenic and allergenic filamentous fungus Aspergillus fumigatus. Nat. Cell Biol. 2005, 438, 1151-1156. [CrossRef]

40. Pel, H.J.; De Winde, J.H.; Archer, D.B.; Dyer, P.S.; Hofmann, G.; Schaap, P.J.; Turner, G.; De Vries, R.P.; Albang, R.; Albermann, K.; et al. Genome sequencing and analysis of the versatile cell factory Aspergillus niger CBS 513.88. Nat. Biotechnol. 2007, 25, 221-231. [CrossRef]

41. Ward, N.; Moreno-Hagelsieb, G. Quickly Finding Orthologs as Reciprocal Best Hits with BLAT, LAST, and UBLAST: How Much Do We Miss? PLoS ONE 2014, 9, e101850. [CrossRef]

42. R Core Computing Team. R: A Language and Environment for Statistical Computing; R Found. Stat. Comput: Vienna, Austria, 2019.

43. Blighe, K. PCAtools: Everything Principal Components Analysis; R Packag. Version 1.2.0; R Team: Vienna, Austria, 2019.

44. Ritchie, M.E.; Phipson, B.; Wu, D.; Hu, Y.; Law, C.W.; Shi, W.; Smyth, G.K. limma powers differential expression analyses for RNA-sequencing and microarray studies. Nucleic Acids Res. 2015, 43, e47. [CrossRef]

45. Castillo, D.; Gálvez, J.M.; Herrera, L.J.; Román, B.S.; Rojas, F.; Rojas, I. Integration of RNA-Seq data with heterogeneous microarray data for breast cancer profiling. BMC Bioinform. 2017, 18, 506. [CrossRef]

46. Wickham, H. Ggplot2: Elegant Graphics for Data Analysis; Springer: Verlag, NY, USA, 2016; ISBN 978-3-319-24277-4.

47. Langfelder, P.; Horvath, S. WGCNA: An R package for weighted correlation network analysis. BMC Bioinform. 2008, 9, 1-13. [CrossRef]

48. Langfelder, P.; Horvath, S. FastRFunctions for Robust Correlations and Hierarchical Clustering. J. Stat. Softw. 2012, 46, 1-17. [CrossRef]

49. Zhang, B.; Horvath, S. A General Framework for Weighted Gene Co-Expression Network Analysis. Stat. Appl. Genet. Mol. Biol. 2005, 4, 17. [CrossRef] [PubMed]

50. Priebe, S.; Kreisel, C.; Horn, F.; Guthke, R.; Linde, J. FungiFun2: A comprehensive online resource for systematic analysis of gene lists from fungal species. Bioinform. 2015, 31, 445-446. [CrossRef] [PubMed]

51. Ruepp, A.; Zollner, A.; Maier, D.; Alberman, K.; Hani, J.; Mokrejs, M.; Tetko, I.; Güldener, U.; Mannhaupt, G.; Münsterkö, M.; et al. The Funcat, a functional annotation scheme for systematic classification of proteins from whole genomes. Nucleic Acids Res. 2004, 32, 5539-5545. [CrossRef] [PubMed]

52. Love, M.; Huber, W.; Anders, S. Moderated estimation of fold change and dispersion for RNA-seq data with DESeq2. Genome Biol. 2014, 15, 550. [CrossRef] [PubMed]

53. Langfelder, P.; Horvath, S. Eigengene networks for studying the relationships between co-expression modules. BMC Syst. Biol. 2007, 1, 54. [CrossRef] [PubMed]

54. D'Enfert, C. Fungal Spore Germination: Insights from the Molecular Genetics of Aspergillus nidulansandNeurospora crassa. Fungal Genet. Biol. 1997, 21, 163-172. [CrossRef] 
55. Lindsey, R.; Cowden, S.; Hernández-Rodríguez, Y.; Momany, M. Septins AspA and AspC Are Important for Normal Development and Limit the Emergence of New Growth Foci in the Multicellular Fungus Aspergillus nidulans. Eukaryot. Cell 2009, 9, 155-163. [CrossRef]

56. Bartnicki-Garcia, S.; Bartnicki, D.D.; Gierz, G. Determinants of fungal cell wall morphology: The vesicle supply center. Can. J. Bot. 1995, 73, 372-378. [CrossRef]

57. Fischer-Parton, S.; Parton, R.M.; Hickey, P.C.; Dijksterhuis, J.; Atkinson, H.A.; Read, N.D. Confocal microscopy of FM4-64 as a tool for analysing endocytosis and vesicle trafficking in living fungal hyphae. J. Microsc. 2000, 198, 246-259. [CrossRef]

58. Bracker, C.E. Diversity and dynamics of the Spitzenkörper in growing hyphal tips of higher fungi. Protoplasma 1996, 195, 90-111. [CrossRef]

59. Köhli, M.; Galati, V.; Boudier, K.; Roberson, R.W.; Philippsen, P. Growth-speed-correlated localization of exocyst and polarisome components in growth zones of Ashbya gossypii hyphal tips. J. Cell Sci. 2008, 121, 3878-3889. [CrossRef]

60. Harris, S.D.; Read, N.D.; Roberson, R.W.; Shaw, B.; Seiler, S.; Plamann, M.; Momany, M. Polarisome Meets Spitzenkörper: Microscopy, Genetics, and Genomics Converge. Eukaryot. Cell 2005, 4, 225-229. [CrossRef]

61. Pinar, M.; Pantazopoulou, A.; Arst, H.N.; Peñalva, M.A. Acute inactivation of theAspergillus nidulans Golgi membrane fusion machinery: Correlation of apical extension arrest and tip swelling with cisternal disorganization. Mol. Microbiol. 2013, 89, 228-248. [CrossRef] [PubMed]

62. Virag, A.; Lee, M.P.; Si, H.; Harris, S.D. Regulation of hyphal morphogenesis by cdc42 and rac1 homologues in Aspergillus nidulans. Mol. Microbiol. 2007, 66, 1579-1596. [CrossRef] [PubMed]

63. Araujo-Palomares, C.L.; Richthammer, C.; Seiler, S.; Castro-Longoria, E. Functional Characterization and Cellular Dynamics of the CDC-42-RAC-CDC-24 Module in Neurospora crassa. PLoS ONE 2011, 6, e27148. [CrossRef] [PubMed]

64. Si, H.; Rittenour, W.R.; Harris, S.D. Roles of Aspergillus nidulans Cdc42/Rho GTPase regulators in hyphal morphogenesis and development. Mycologia 2016, 108, 543-555. [CrossRef]

65. Riquelme, M.; Aguirre, J.; Bartnicki-García, S.; Braus, G.H.; Feldbrügge, M.; Fleig, U.; Hansberg, W.; Herrera-Estrella, A.; Kämper, J.; Kück, U.; et al. Fungal Morphogenesis, from the Polarized Growth of Hyphae to Complex Reproduction and Infection Structures. Microbiol. Mol. Biol. Rev. 2018, 82. [CrossRef]

66. Virag, A.; Harris, S.D. The Spitzenkörper: A molecular perspective. Mycol. Res. 2006, 110, 4-13. [CrossRef] [PubMed]

67. Takeshita, N.; Fischer, R. On the role of microtubules, cell end markers, and septal microtubule organizing centres on site selection for polar growth in Aspergillus nidulans. Fungal Biol. 2011, 115, 506-517. [CrossRef] [PubMed]

68. Higashitsuji, Y.; Herrero, S.; Takeshita, N.; Fischer, R. The Cell End Marker Protein TeaC Is Involved in Growth Directionality and Septation in Aspergillus nidulans. Eukaryot. Cell 2009, 8, 957-967. [CrossRef]

69. Harris, S.D.; Momany, M. Polarity in filamentous fungi: Moving beyond the yeast paradigm. Fungal Genet. Biol. 2004, 41, 391-400. [CrossRef] [PubMed]

70. Meyer, V.; Arentshorst, M.; Hondel, C.A.V.D.; Ram, A.F. The polarisome component SpaA localises to hyphal tips of Aspergillus niger and is important for polar growth. Fungal Genet. Biol. 2008, 45, 152-164. [CrossRef]

71. Machesky, L.M.; Gould, K.L. The Arp2/3 complex: A multifunctional actin organizer. Curr. Opin. Cell Biol. 1999, 11, 117-121. [CrossRef]

72. Lipschutz, J.H.; Mostov, E.K. Exocytosis: The Many Masters of the Exocyst. Curr. Biol. 2002, 12, R212-R214. [CrossRef]

73. TerBush, D.R.; Maurice, T.; Roth, D.; Novick, P. The Exocyst is a multiprotein complex required for exocytosis in Saccharomyces cerevisiae. EMBO J. 1996, 15, 6483-6494. [CrossRef]

74. Seiler, S.; Plamann, M. The Genetic Basis of Cellular Morphogenesis in the Filamentous FungusNeurospora crassa. Mol. Biol. Cell 2003, 14, 4352-4364. [CrossRef]

75. Punt, P.J.; Seiboth, B.; Weenink, X.O.; Van Zeijl, C.; Lenders, M.; Konetschny, C.; Ram, A.F.J.; Montijn, R.; Kubicek, C.P.; Van Den Hondel, C.A.M.J.J. Identification and characterization of a family of secretion-related small GTPase-encoding genes from the filamentous fungus Aspergillus niger: A putative SEC4 homologue is not essential for growth. Mol. Microbiol. 2001, 41, 513-525. [CrossRef] [PubMed]

76. Powers-Fletcher, M.V.; Feng, X.; Krishnan, K.; Askew, D.S. Deletion of the sec4 Homolog srgA from Aspergillus fumigatus Is Associated with an Impaired Stress Response, Attenuated Virulence and Phenotypic Heterogeneity. PLoS ONE 2013, 8, e66741. [CrossRef] [PubMed]

77. Gupta, G.D.; Heath, I.B. Predicting the distribution, conservation, and functions of SNAREs and related proteins in fungi. Fungal Genet. Biol. 2002, 36, 1-21. [CrossRef]

78. Atkinson, H.A.; Daniels, A.; Read, N.D. Live-cell imaging of endocytosis during conidial germination in the rice blast fungus, Magnaporthe grisea. Fungal Genet. Biol. 2002, 37, 233-244. [CrossRef]

79. Van Leeuwen, M.; Golovina, E.; Dijksterhuis, J. The polyene antimycotics nystatin and filipin disrupt the plasma membrane, whereas natamycin inhibits endocytosis in germinating conidia of Penicillium discolor. J. Appl. Microbiol. 2009, 106, 1908-1918. [CrossRef] [PubMed]

80. Steinberg, G. Endocytosis and early endosome motility in filamentous fungi. Curr. Opin. Microbiol. 2014, 20, 10-18. [CrossRef]

81. De Vries, R.P.; Riley, R.; Wiebenga, A.; Aguilar-Osorio, G.; Amillis, S.; Uchima, C.A.; Anderluh, G.; Asadollahi, M.; Askin, M.; Barry, K.; et al. Comparative genomics reveals high biological diversity and specific adaptations in the industrially and medically important fungal genus Aspergillus. Genome Biol. 2017, 18, 1-45. [CrossRef] 
82. Merrick, B.A.; Phadke, D.P.; Auerbach, S.S.; Mav, D.; Stiegelmeyer, S.M.; Shah, R.R.; Tice, R.R. RNA-Seq Profiling Reveals Novel Hepatic Gene Expression Pattern in Aflatoxin B1 Treated Rats. PLoS ONE 2013, 8, e61768. [CrossRef]

83. Zhao, S.; Fung-Leung, W.-P.; Bittner, A.; Ngo, K.; Liu, X. Comparison of RNA-Seq and Microarray in Transcriptome Profiling of Activated T Cells. PLoS ONE 2014, 9, e78644. [CrossRef]

84. Steenwyk, J.L.; Shen, X.-X.; Lind, A.L.; Goldman, G.H.; Rokas, A. A Robust Phylogenomic Time Tree for Biotechnologically and Medically Important Fungi in the Genera Aspergillus and Penicillium. mBio 2019, 10, e00925-19. [CrossRef]

85. Kang, S.E.; Momany, M. Sporulation environment drives phenotypic variation in the pathogen Aspergillus fumigatus. bioRxiv 2019, 797076. [CrossRef]

86. Wan, Q.; Tang, J.; Han, Y.; Wang, D. Co-expression modules construction by WGCNA and identify potential prognostic markers of uveal melanoma. Exp. Eye Res. 2018, 166, 13-20. [CrossRef] [PubMed]

87. Guo, Y.; Ma, J.; Xiao, L.; Fang, J.; Li, G.; Zhang, L.; Xu, L.; Lai, X.; Pan, G.; Chen, Z. Identification of key pathways and genes in different types of chronic kidney disease based on WGCNA. Mol. Med. Rep. 2019, 20, 2245-2257. [CrossRef] [PubMed]

88. Di, Y.; Chen, D.; Yu, W.; Yan, L. Bladder cancer stage-associated hub genes revealed by WGCNA co-expression network analysis. Hereditas 2019, 156, 1-11. [CrossRef]

89. Hu, V.W.; Bi, C. Phenotypic Subtyping and Re-analyses of Existing Transcriptomic Data from Autistic Probands in Simplex Families Reveal Differentially Expressed and ASD Trait-Associated Genes. Front. Neurol. 2020, 11, 578972. [CrossRef] [PubMed]

90. Li, X.; He, Y.; Hao, C.; Li, X.; Li, X. Weighted gene correlation network analysis reveals novel regulatory modules associated with recurrent early pregnancy loss. Biosci. Rep. 2020, 40, 40. [CrossRef]

91. Li, Y.-J.; Zhou, T.; Zhang, J.; Zhang, L.; Ke, H.; Zhang, C.; Li, P. Clinical trait-connected network analysis reveals transcriptional markers of active psoriasis treatment with Liangxue-Jiedu decoction. J. Ethnopharmacol. 2021, 268, 113551. [CrossRef]

92. Fischer, R.; Zekert, N.; Takeshita, N. Polarized growth in fungi-interplay between the cytoskeleton, positional markers and membrane domains. Mol. Microbiol. 2008, 68, 813-826. [CrossRef]

93. Riquelme, M.; Sánchez-León, E. The Spitzenkörper: A choreographer of fungal growth and morphogenesis. Curr. Opin. Microbiol. 2014, 20, 27-33. [CrossRef]

94. Takeshita, N. Coordinated process of polarized growth in filamentous fungi. Biosci. Biotechnol. Biochem. 2016, 80, 1693-1699. [CrossRef] 